\title{
A instituição especializada em tempos de inclusão
}

Roseli Albino dos Santos* Suelene Regina Mendonça** Mercia Cunha Oliveira***

\section{Resumo}

Este estudo buscou investigar os significados e sentidos sobre inclusão escolar e deficiência produzidos por um grupo de profissionais que atua em uma instituição especializada localizada em um município do interior do estado de São Paulo. Para a coleta de dados foi utilizado um roteiro de entrevista semiestruturada aplicada à diretora da instituição, a duas coordenadoras pedagógicas e a cinco professoras. Os dados foram submetidos a uma análise descritivo-interpretativa. Os resultados indicaram que as profissionais atribuem, unicamente, aos alunos com deficiência intelectual, e suas condições pessoais a responsabilidade pelo seu desenvolvimento e inclusão escolar. A ênfase dos discursos recai sobre a incapacidade do aluno e a imutabilidade da deficiência. Observa-se que as narrativas não revelam posicionamento crítico dos profissionais aos processos educativos voltados a essa população. Os profissionais que atuam na instituição especializada ainda apresentam uma concepção de deficiência baseada na incapacidade do aluno e, apesar de defenderem o direito desses alunos à inclusão escolar, ainda manifestam receio do que estes irão encontrar fora dos muros da instituição, revelando atitudes de superproteção e desconhecimento do papel da instituição especializada em tempos de inclusão. Conclui-se que as concepções sobre a deficiência intelectual e a inclusão escolar, apresentadas pelos profissionais, podem contribuir muito mais para a reiteração da exclusão escolar, historicamente voltada a essa população, do que para sua efetiva inclusão no sistema escolar de ensino.

Palavras-chave: Instituição especializada; Deficiência; Inclusão; Profissionais.

\footnotetext{
* Professora Doutora da Universidade de Taubaté, Taubaté, São Paulo, Brasil.

** Professora Doutora da Universidade de Taubaté, Taubaté, São Paulo, Brasil.

*** Professora Doutora da Universidade de Taubaté, Taubaté, São Paulo, Brasil.
} 


\title{
The Specialized school in time of inclusion
}

\begin{abstract}
This study has the objective to investigate the meanings about school inclusion and disability, produced by a group of professionals engaged in a specialized school located in a city in the state of São Paulo. The metodology used was semi-structured and structured interviews with the director of the institution, two pedagogical coordinators and five teachers. Data were subjected to a descriptive-interpretative analysis. The results indicated that professionals attribute the responsibility for self development, only to students with intellectual disabilities. The emphasis of the speeches falls on the inability of the student and the immutability of disability. It is observed that the narratives do not reveal critical positioning of professional educational processes involving this population. The professionals who work in specialized institution still have a conception of disability based on the inability of the student and, despite defending the right of these students to school inclusion, these professionals still manifest fear of what they will find outside the walls of the institution, revealing attitudes and overprotection ignorance of the role of specialized institution in times of inclusion. We conclude that the conceptions about intellectual disability and inclusive education presented by professionals can contribute much more to the reiteration of school exclusion, historically focused on this population than for its actual inclusion in the school system of education.
\end{abstract}

Key-words: Specialized school; Disability; Inclusion; Professionals.

\section{Introdução}

\section{A instituição especializada: apoio à inclusão ou reiteração da exclusão de alunos com deficiência intelectual?}

Historicamente, a situação das pessoas com deficiência passou por diferentes formas: do abandono à própria sorte ao isolamento em instituições especializadas e a segregação em classes especiais, criadas nas escolas regulares, as quais tiveram grande ampliação na década de 1970.

Conforme Bueno (2004), a institucionalização da educação voltada às pessoas com deficiência ocorreu no final do império com a criação do Imperial Instituto dos Surdos-Mudos, atualmente, denominado Instituto Nacional de Educação para Surdos (INES) e o Imperial Instituto dos Meninos Cegos, atualmente, Instituto Benjamin Constant, ambos no Rio de Janeiro.

$\mathrm{Na}$ visão desse autor, a institucionalização da educação especial cumpriu duas funções: atender àqueles que, por suas condições pessoais, não tinham acesso à educação ao mesmo tempo em que os isolava do convívio social com os demais. 
Com o advento das classes especiais, muitos alunos com deficiência foram encaminhados para essa modalidade de ensino. No entanto, apesar da classe especial ser considerada um espaço de passagem para os alunos com deficiência, a grande maioria, segundo apontam diversas pesquisas (DECHICHI, 1993; SANTOS, 2002), ali permaneceu por muito tempo sem aprender o suficiente para acompanhar as classes de ensino regular.

O pensamento predominante, nessa época, era o da integração, que significava que os alunos com deficiência deveriam frequentar as classes especiais com professor especializado até que se tornassem aptos a serem matriculados nas classes comuns. Quer dizer, o aluno deveria demonstrar que tinha condições para ser inserido na modalidade regular de ensino. Como o que predominava nessa época era a visão médica da deficiência, os professores acabaram por aplicar métodos oriundos da área da saúde em detrimento dos métodos pedagógicos. Quanto aos alunos surdos, segundo Soares (1999), o professor da classe especial para surdos tinha que cumprir duas funções: a de professor e a de terapeuta da fala, conforme a orientação da Proposta Curricular (1979) que enfatizava o aprendizado da linguagem oral desses alunos. Também Bueno (2004) apontou que os alunos com deficiência, mesmo permanecendo anos a fio nessa modalidade de ensino, não ultrapassaram as séries iniciais do ensino fundamental.

O aumento do número de instituições voltadas ao atendimento de alunos com deficiência intelectual foi maior do que o das instituições destinadas às outras deficiências (BUENO, 2004). No que diz respeito às classes especiais - forma predominante de ensino público - o encaminhamento desses alunos era realizado com base no quociente intelectual (QI) alcançado pelos mesmos em testes psicológicos. A ideia era a constituição de classes homogêneas, como se isso fosse possível. Não se considerava o fato de que, mesmo apresentando o mesmo tipo de deficiência, cada aluno é único, com origens e histórias de vidas diferentes.

O cenário educacional brasileiro, em relação à educação das pessoas/crianças adolescentes com deficiência, começou a mudar efetivamente a partir dos anos de 1988, com a Constituição Federativa do Brasil (BRASIL, 1988), o Estatuto da Criança e do Adolescente (BRASIL, 1990) e a promulgação da Lei de Diretrizes e Bases da Educação Nacional, LDB n. 9394/96- (BRASIL, 1996). Outros marcos importantes na mudança dos rumos da educação das pessoas com deficiência foram a Declaração Mundial de Educação para Todos (1990), a Declaração de Salamanca (UNESCO, 1994) e a Convenção de Guatemala (2001). Os movimentos consolidados nos documentos mencionados influenciaram o desenvolvimento das políticas e ações voltadas para a educação inclusiva no Brasil.

Os dados divulgados pelo INEP/MEC (BRASIL, 2009) mostram que houve um aumento de alunos com deficiências, matriculados na educação básica entre os anos de 2003 a 2008. Em 2008, dos 695.699 alunos com deficiência matriculados, 375.775 estavam nas classes comuns do ensino fundamental, enquanto 319.924 estavam matriculados em estabelecimentos exclusivamente especializados e em classes especiais do ensino regular. Esses dados mostram que, apesar das políticas públicas 
de educação inclusiva, ainda há um número significativo de alunos matriculados em instituições especializadas e classes especiais. Dentre eles, o maior número diz respeito aos alunos que apresentam deficiência intelectual, foco dessa pesquisa.

Considerando a importância histórica das instituições especializadas no cenário educacional brasileiro e no atendimento de pessoas com deficiência na perspectiva da inclusão escolar, esse estudo teve como objetivo investigar os significados e sentidos da inclusão escolar e a deficiência para os professores, os coordenadores e o diretor de uma instituição especializada.

\section{Metodologia}

A presente pesquisa foi desenvolvida em uma instituição especializada para o atendimento de crianças, jovens e adultos com deficiência intelectual, localizada em um município no interior do estado de São Paulo, fundada na década de 1960.

O quadro de funcionário da Instituição era composto pela direção (uma diretora e duas coordenadoras pedagógicas); núcleo técnico-pedagógico (15 profissionais da área da saúde) e corpo docente, constituído por 27 professores, sendo 1 da Educação Infantil, 05 do Ensino Fundamental e 21 professores de jovens e adultos nos programas e oficinas.

Para a coleta dos dados, foi utilizado um roteiro de entrevista semiestruturada aplicado à diretora, a duas coordenadoras pedagógicas e a cinco professoras, todas elas com formação em Pedagogia, cujas idades variavam entre 31 a 46 anos; o tempo de trabalho, na instituição especializada, variava de 09 meses a 18 anos.

\section{A visão dos profissionais sobre as possibilidades educacionais do aluno com deficiência intelectual}

Analisando o conteúdo das entrevistas realizadas com a diretora, as coordenadoras e as professoras, foi possível observar que alguns profissionais, ao falarem de suas visões sobre o aluno com deficiência intelectual, enfatizam os limites impostos pela deficiência e a necessidade do atendimento diferenciado, do cuidado especial, considerando que nem todos poderiam ser inseridos no ensino regular, como podemos observar nos relatos:

São alunos muito capazes, mas existem alunos que não tem condições de serem inseridos no sistema regular de ensino. (Diretora)

Criança como todas as outras, porém com certa lentidão no processo de aprendizagem e que, portanto, necessita de atendimento especial. A instituição tem o papel de zelar pelas crianças como um todo. São crianças que brincam, entendem, participam, mas que precisam de atenção maior. (Coordenadora) 
São pessoas mais do que especiais, que necessitam de ajuda, auxílio. É o aluno com dificuldade de entendimento pedagógico. (Professora 1)

Um aluno que precisa de todo o apoio para que consiga desenvolver todo seu potencial: motor, cognitivo, mental, intelectual, afetivo. (Coordenadora 1 )

A ênfase na deficiência intelectual como limitadora do desenvolvimento dos indivíduos pode gerar ações educativas pouco estimuladoras. Alguns estudos na área da educação especial (GLAT, 1999; KASSAR, 1995; MACHADO, 1997; MIRANDA, 1993) apontam que parte dos trabalhos pedagógicos, direcionados a alunos com deficiência intelectual, parecem estar centrados nas incapacidades do sujeito e na imutabilidade da deficiência. Tais perspectivas podem vir a fomentar preconceitos sociais e, consequentemente, o isolamento da pessoa com deficiência. Neste sentido, Glat $(1989$, p. 22) afirma que "[...] pessoas rotuladas como deficientes mentais se apresentam mais dependentes e incapazes do que seria resultado de sua condição orgânica, por terem aprendido a desempenhar o papel de deficientes". Os rótulos ou estigmas atribuídos às pessoas com deficiência intelectual podem impedí-las de participarem efetivamente dos processos sociais no quais, inevitavelmente, estão inseridos.

Outros profissionais da instituição, entretanto, consideram que o aluno com deficiência intelectual, se estimulado, pode desenvolver diversas habilidades. Este grupo não nega a deficiência intelectual, entretanto, parece acreditar que o estímulo externo pode ajudar no desenvolvimento das pessoas e na superação dos limites impostos pela deficiência:

O aluno "apaiano" é aquele que tem dificuldade de aprendizagem e de autonomia, mas pode ter seus problemas como algo reversível. (Professora 3)

Não vejo a deficiência, ou melhor, não desconsidero a deficiência, mas acho que são pessoas muito capazes (apesar das limitações). Procuro ajudá-los através de recursos. (Professora 4)

Este posicionamento vem ao encontro dos postulados de Vygotsky (1997a) Segundo ele, é preciso considerar que a criança deficiente intelectual não está constituída apenas pela deficiência e carências, pois seu organismo se reestrutura como todo único. A sua personalidade vai sendo constituída como um todo e compensada pelos processos de desenvolvimento da criança. Nesse sentido, ressalta-se a importância da qualidade das ações pedagógicas propostas à criança pelo professor para que a aprendizagem impulsione o seu desenvolvimento.

Para la educación del niño mentalmente retrasado és importante conocer cómo se desarrolla, no es importante la insuficiência em si, la carência, el déficit, el defecto em si, sino la reacción que nace em la personalidad del niño, durante el proceso de dasarrolo, em respuesta a la dificultad con que tropieza y que deriva de esa insuficiência. (VYGOTSKY, 1997a, p. 134) 
Para Vygotsky (1997a), a todo momento o desenvolvimento da criança deficiente intelectual está sendo influenciado por elementos externos positivos e negativos que podem favorecer ou dificultar o seu desenvolvimento. Vygotsky (1997a) considerava que, mesmo que os alunos com Deficiência Intelectual precisem de um tempo maior para aprender, aprendem menos que os outros alunos sem deficiência e mesmo que se lhes ensine de outros modos - aplicando métodos e procedimentos especiais adaptados às suas características específicas; devem estudar o mesmo que todos os demais alunos, receber a mesma preparação para a vida, para que possam participar dela futuramente, em certa medida, junto com os outros.

\section{Posicionamentos das profissionais da instituição a respeito da inclusão}

Muito embora as discussões em relação à inclusão tenham se ampliado na última década, percebe-se pouco avanço na sua concretização. Ao analisar as produções que tratam da inclusão das pessoas com deficiência no ensino regular, Carmo (2001) aponta duas tendências dominantes: a primeira, a qual o autor denomina "inclusivista", diz respeito àqueles que respaldam a inclusão em bases legais; e, a segunda, àqueles que atrelam a inclusão à adaptação da escola, a qual o autor denomina "adaptadores" ou "restauradores". Segundo o autor, na primeira tendência:

[...] a realidade objetiva e o movimento histórico das funções da educação e da escolarização não são considerados, o problema eminente de natureza social fica reduzido a uma questão legal. (CARMO, 2001, p. 44).

Assim, os seguidores dessa linha de pensamento, ou seja, os "inclusivistas" acreditam na inclusão sob o ponto de vista da legalidade, da norma jurídica e, consequentemente, "[...] forçam e colocam em prática uma ação completamente desarticulada e sem compromisso com a realidade objetiva das escolas regulares brasileiras." (ibidem). Já, os seguidores da segunda tendência, ou seja, os "adaptadores", parecem não perceber a incompatibilidade histórica que sempre existiu entre os projetos político-pedagógicos das escolas regulares e das escolas especiais. Dessa forma, o autor afirma que os debates e produções, acerca do tema inclusão, desconsideram, não raramente, seu movimento e suas consequências e levam a discussão para lugar e tempo abstratos. Neste sentido, interessou-nos conhecer o posicionamento dos profissionais que atuam na instituição especializada acerca desse assunto.

Nos depoimentos da diretora e das coordenadoras, foi possível verificar a preocupação em manter os alunos na instituição, alegando que alguns, em decorrência das características pessoais, não teriam condições de frequentar uma escola regular. Outra preocupação levantada foi em relação ao possível fechamento da instituição especializada em decorrência da inclusão dos alunos no ensino regular, como podemos observar nos relatos:

Existe uma preocupação da Instituição com relação à inclusão, mas sabemos que existem alunos que não tem condições de serem inseridos no sistema regular de ensino. A A. acredi- 
ta muito na inclusão social, porém para a inclusão pedagógica nem todos estão diante destas circunstâncias, há limitações. Se estes alunos estão aprendendo aqui porque não estarem aqui? Por isso, sou a favor da inclusão para os que têm boas condições de estarem lá. A sociedade não está preparada para receber o deficiente. (Diretora)

A inclusão tem que ser feita, mas não como o governo acredita. Existem alunos que não tem condições de estarem no ensino regular. O ideal seria um trabalho paralelo com a rede comum para que os professores sanem as dificuldades do aluno, em ambas as organizações (especializada e comum). Portanto, eu não acredito na inclusão enquanto o ensino regular não estiver preparado para receber o deficiente. Sou contra a lei que visa acabar com a instituição especializada. Acho que essa tem que ser mantida para melhor atendimento do aluno. (Coordeandora 1)

Desde quando iniciei minha atuação na instituição acredito na inclusão social do aluno. No entanto, a inclusão pedagógica é ainda utopia. Nos programas que desenvolvo, as deficiências são agravadas. Crianças que não tem fixação dos conceitos e que, muitas vezes, são agressivas. Acho que estamos pulando etapas. Seria necessário inicialmente um trabalho social preparando a sociedade para envolver-se com o deficiente. (Coordenadora 2)

Novamente, observa-se, nos relatos, a ênfase nos limites impostos pela deficiência intelectual. Assim, ao atribuir aos alunos e suas condições pessoais a responsabilidade pelo seu desenvolvimento e inclusão escolar, as concepções das profissionais parecem estar centradas nas incapacidades do sujeito e na imutabilidade da deficiência, tecendo poucas críticas aos processos educativos voltadas a esta população, tanto na escola especial, quanto na escola regular. Nos depoimentos, fica ainda evidente o distanciamento entre os dois modelos de ensino (escola regular x escola especial).

Nesse sentido, os trabalhos de Vygotsky (1989) oferecem grandes contribuições no entendimento da deficiência intelectual e dos processos de ensino e aprendizagem. O interesse de Vygotsky (1989) era, basicamente, sobre o funcionamento intelectual do ser humano, enquanto parte de uma realidade sociocultural determinada, propondo que a deficiência não é tanto de caráter biológico, quanto social.

Vygotsky (1989) fazia grandes críticas à escola especial que marginalizava a criança, que a isolava das relações sociais com as crianças da mesma idade e da sociedade em geral. Ao propor que as crianças deficientes deveriam ser educadas de forma semelhante a das crianças normais, sugere que elas devem ser educadas conjuntamente, o que as ajudaria no desenvolvimento psíquico, físico e na compensação e correção dos defeitos.

As suas observações sobre crianças com diferentes tipos de deficiência se baseavam em um enfoque qualitativo, que procurava elucidar a organização peculiar 
de suas funções e condutas. Vygotsky (1997b) não concebia as deficiências em termos de diminuição quantitativa de determinadas funções, senão como uma organização qualitativamente diferente. Uma criança deficiente não é uma criança normal menor ou simplesmente menos capaz de exercer certas habilidades, ela possui uma estrutura funcional peculiar.

De outra parte, as professoras aparentemente têm uma visão mais positiva em relação às possibilidade da inclusão escolar dos alunos com deficiência intelectual, mas questionam a realidade social e escolar:

Eu acho que o processo está ainda muito cru pela não aceitação das pessoas de fora. A sociedade não está preparada. Nem mesmo o profissional da educação está preparado. Ainda há muito a ser feito. A estrutura das escolas e do sistema teria que ser diferentes para que os alunos não fiquem esquecidos no fundo da sala. (Professora l)

A sociedade não está preparada, as demais crianças estão à frente. Há falta de respeito, despreparo profissional (o que na verdade é uma busca pessoal). Não fosse tudo isso eu investiria nessa idéia, embora eu acredito muito nisso e em meus alunos. (Professora 2)

Sou favorável à inclusão desde que haja os recursos necessários (profissional e material) para a concretização desta. (Professora 3)

Sou muito a favor da inclusão, porém, é algo que precisa ser muito estudado e trabalhado. Da forma que se pretende, irá, certamente, chocar...Há que ser realizado um trabalho em família, com a sociedade e, principalmente, com os profissionais (capacitação dos professore). O ideal para a inclusão é pensar em todos estes elementos e mais, na estrutura física dos prédios, no número de aluno em sala de aula, nos que serão incluídos, pois, nem todos os casos têm condições de estar na rede regular de ensino. Para estes seria exposição e sofrimento. (Professora 4)

Existem casos que são possíveis, porém deve haver muito estudo específico para cada caso para que a rede regular possa receber este aluno e que este aluno consiga se desenvolver permanentemente e não ser apenas mais um número na sala. Não há ainda preparo estrutural nem profissional da escola comum para trabalhar com a inclusão. (Professora 5)

Todas as dificuldades para a concretização da inclusão, na visão dessas professoras, estão além dos muros da instituição especializada, como a falta de preparo da sociedade, dos professores, das estruturas físicas dos prédios das escolas regulares. Isso sugere que o desejo dos professores é o de proteger os alunos dos desafios que terão que enfrentar ao serem incluídos no ensino regular. Os professores parecem acreditar que, diante de tantas dificuldades que os alunos com deficiência intelectual terão que enfrentar fora da instituição, o melhor, então, é que permaneçam ali. 
Entretanto, a permanência do aluno na instituição especializada pode limitar o seu processo de desenvolvimento. Neste sentido, Vygostsky (1997a) critica, de forma contundente, a escola especial. Para o autor, a permanência desses alunos na instituição especializada induz a um ensino centrado nos limites intelectuais e sensoriais, o que resulta na restrição das suas oportunidades de desenvolvimento.

Para Vygotsky (1997c), a criança com deficiência deve estudar junto com as crianças sem deficiência, pois, segundo ele, as mediações que ocorrem no grupo favorecem o desenvolvimento das funçoes psicológicas superiores exatamente pela existência da diferença no nível intelectual das crianças que compõem o grupo.

\section{Considerações finais}

Mesmo com a intensificação do desenvolvimento das políticas e ações de inclusão escolar de alunos com deficiências, ainda hoje, existe um número significativo desses alunos nas instituições especializadas, conforme os dados numéricos divulgados pelo MEC/INEP (BRASIL, 2009), a maioria são os que apresentam a deficiência intelectual. A existência de legislação, que dispõem sobre os direitos dessas pessoas de conviverem com a família e seus pares, de estudarem em escolas comuns, terem acesso ao trabalho e aos espaços de lazer e cultura, enfim, de participarem de todas as atividades da vida cotidiana, não tem sido suficiente.

Essa pesquisa aponta que os profissionais que atuam na instituição especializada ainda apresentam uma concepção de deficiência baseada na incapacidade do aluno e, apesar de defenderem o direito desses alunos à inclusão escolar, ainda manifestam receio do que estes irão encontrar fora dos muros da instituição, revelando atitudes de superproteção e o desconhecimento do papel da instituição especializada em tempos de inclusão. Como podemos verificar no depoimento a seguir:

[...] Se estes alunos estão aprendendo aqui porque não estarem aqui?. (Diretora)

Sou contra a lei que visa acabar com a instituição especializada. Acho que essa tem que ser mantida para melhor atendimento do aluno. (Coordenadora 1)

Na realidade, as políticas nacionais de educação especial na perspectiva da educação inclusiva (BRASIL, 2007) preveem que a educação especial atue de forma articulada com o ensino comum, no sentido de atender às necessidades especiais dos alunos. O que se pretende, na realidade, é romper com a ideia que vem perdurando há décadas de que a educação especial, oferecida em instituições especializadas ou classes especiais, substitui a escola de ensino regular, mesmo com a dicotomia que ainda perdura entre ensino regular e educação especial. O que não se percebe é que a permanência do aluno com deficiência intelectual somente na instituição especializada acaba por reforçar o estigma da diferença e o sentimento de menos valia, fazendo com que esses alunos não avancem em seu processo de aprendizagem e desenvolvimento. 
As investigações de Vygotsky (1997c) sobre as funções psíquicas superiores, durante o seu processo de desenvolvimento, tem origem social, tanto no aspecto filogenético quanto nos aspectos ontogênicos:

[...] funciones psíquicas superiores (el pensamiento en conceptos, el linguaje racional, la memoria lógica, la atención voluntaria, etc.) se han formado durante el período histórico de desarrollo de la humanidad e deben su origen, non a la evolución biológica que conformó el biótipo de ser humano, sino a su desarrolo histórico como ser social. Sólo en el proceso de la vida social colectiva se han elaborado y desarrollado todas las formas superiores de actividade intelectual propias del hombre. (VYGOSTSKY, 1997c, p. 213-214)

Nesse sentido, é importante reiterar a necessidade da inclusão escolar de alunos com deficiência intelectual na escola comum, estudando junto com os alunos da mesma faixa etária e sem deficiência. A decisão desses profissionais em manter esses alunos em sistemas segregados de ensino, como a instituição especializada, pode evidenciar a descrença dos mesmos na possibilidade de que os alunos com deficiência intelectual desenvolvam as funções psicológicas superiores e, em consequência disso, as práticas pedagógicas sejam retrospectivas, isto é, orientadas para o avanço e aperfeiçoamento de processos elementares.

A separação de alunos com deficiência do grupo de alunos sem deficiência dificulta o desenvolvimento da comunicação coletiva, de colaboração e de interação desses alunos com as pessoas que o rodeiam. Enfim, essa separação dificulta o desenvolvimento social, o que acarreta o desenvolvimento incompleto das funções psicológicas superiores, pois, para Vygotsky (1997c) a seleção de coletividades homogêneas de crianças com deficiência intelectual as priva da colaboração coletiva e da comunicação com outras crianças mais adiantadas, e tem como consequência um desenvolvimento incompleto dessas funções. É possível que a concepção dos profissionais da instituição especializada sobre o aluno com deficiência intelectual e sobre a inclusão escolar estejam relacionadas ao desconhecimento sobre processos de desenvolvimento psicológico da criança com este tipo de deficiência e de que coletividades heterogêneas formadas pelo nível intelectual são as mais desejáveis, estáveis e duráveis para o processo educativo.

Talvez, o maior entrave para a concretização da inclusão escolar de alunos com deficiência intelectual nos sistemas comuns de ensino seja a visão de muitos profissionais, ainda calcada na classificação psicométrica. Essa classificação induz à homogeneização dos grupos de alunos, das práticas pedagógicas, além de estabelecer limites ao desenvolvimento intelectual dos mesmos, impossibilitando que esses alunos lutem em direção à superação das dificuldades, como defendia Vygotsky (1997c). Conclui-se, portanto, que as concepções sobre a deficiência intelectual e a inclusão identificadas nos dados dessa pesquisa, contribuem para a reiteração da exclusão escolar dessa população de alunos. 


\section{Referências}

BARREIROS, D. Tornar a educação inclusiva. Brasília: UNESCO, 2009.

BRASIL. Estatuto da criança e do adolescente. Lei n. 8.069, de 13 de julho de 1990, Lei n. 8.242, de 12 de outubro de 1991. - 3. ed. - Brasília, DF, 1990: Câmara dos Deputados, Coordenação de Publicações, 2001. Disponível em: 〈http://www.desenvolvimentosocial.sp.gov.br/a2sitebox/arquivos/documentos/182.pdf.〉 Acesso em: 18 abr. 2013.

BRASIL. Constituição da Republica Federativa do Brasil. Diário Oficial da União, Poder Legislativo, Brasília, DF, 1988.

. Decreto no 6.571 , de 17 de setembro de 2008. Dipõe sobre o atendimento educacional especializado, regulamenta o parágrafo único do art.60, da Lei 9.394, de 20 de dezembro de 1996, e acrescenta dispositivo ao Decreto n. 6.253, de 13 de novembro de 2007. Diário Oficial[da] República Federativa do Brasil, Brasília - DF, 18 set. 2008. Seção 1, p. 26.

. Lei no 9.394, de 20 de dezembro de 1996. Estabelece as diretrizes e bases da educação nacional. Diário Oficial [da] República Federativa do Brasil. Brasília, DF , 20 dez. 1996. Disponível em:< http://www6. senado.gov.br/legislacao/ListaTextoIntegral.action?id=75723>Acesso em: 18 abr. 2013.

Decreto no 3.956 , de 8 de outubro de 2001. Promulga a convenção interamericana para eliminação de todas as formas de discriminação contra as pessoas portadoras de deficiência. Diário Oficial [da] República Federativa do Brasil, Brasília-DF, 18 set. 2008. Seção 1, p. 26.

INEP. Censo Escolar, 2009. Disponível em:/http:// http://www.inep.gov.br/basica/censo/default. asp >. Acesso em: 18 abr. 2013.

Ministério da Educação e Cultura. Proposta curricular para deficientes auditivos; manual do professor - didática especial. Divisão de Educação e Distúrbios da Comunicação, DERDIC da Pontifícia Universidade Católica de São Paulo, 1979.

BUENO, J. G. S. Educação Especial Brasileira: integração/segregação do aluno diferente. 2. ed. São Paulo: EDUC, 2004.

CARMO, A. A. do. Inclusão Escolar: Roupa nova em corpo velho. Revista Integração, Brasília: MEC/ SEESP, n. 23, p. 43-47, 2001.

DECHICHI, C. Caracterizando o aluno portador de deficiência mental. 1993. Dissertação (Mestrado), Universidade de São Paulo, São Paulo,1993.

FERREIRA, W. B. Entendendo a discriminação contra estudantes com deficiência na escola. In: FÁVERO, O.; FERREIRA, W.; IRELAND, T.; BARREIROS, D. (Org.). Tornar a Educação Inclusiva. Brasília: UNESCO, 2009. p. 25-54.

GLAT, R. A integração social dos portadores de deficiência: uma reflexão. Rio de Janeiro, Sete Letras, 1989.

GLAT, R; MULLER,T. M. P. Uma professora muito especial: questões atuais em educação. Rio de Janeiro, Sete Letras, 1999.

JANNUZZI, G. de M. A Educação do deficiente mental no Brasil - dos primórdios ao início do século XXI. Campinas, SP: Autores Associados, 2004.

KASSAR, M. de C. M. Ciência e senso comum no cotidiano das classes especiais. Campinas, SP: Papirus, 1995.

Revista Educação Especial | v. 27 | n. 48 | p. 41-52 | jan./abr. 2014

Santa Maria

Disponível em: <http://www.ufsm.br/revistaeducacaoespecial> 
MACHADO, A. M.; SOUSA, M; SAYAO. Y. As classes especiais e uma proposta de avaliação psicológica. In: MACHADO, A. M. et al. Educação especial em debate. São Paulo: Conselho Regional de Psicologia, 1997.

MIRANDA, T. A estruturação do pensamento conceitual em alunos de classe especial - alunos com deficiência ou com atraso intelectual? Dissertação (Mestrado), Universidade Federal de São Carlos, São Carlos, 1993.

SANTOS, R. A. dos. A trajetória escolar de alunos deficientes mentais atendidos em classe especial da Rede Pública Estadual Paulista. 2002. Dissertação (Mestrado), PUC/SP, São Paulo, 2002.

SOARES, M. A. L. A educação do surdo no Brasil. 2. ed. Campinas, SP: Autores Associados, 1999.

UNESCO. Declaração de Salamanca e linha de ação sobre necessidades educativas especiais. Brasília: Corde, 1994.

VYGOTSKY, L. S. Pensamento e Linguagem. 2. ed. São Paulo:. Martins Fontes,1989.

Acerca de los procesos compensatórios em El desarrollo Del niño mentalmente retrasado. Obras escogidas. Fundamentos de Defectologia. Madrid: Visor4, 1997a. $1997 \mathrm{~b}$

El problema del retraso mental. Obras escogidas. Fundamentos de Defectologia. Madrid: Visor4.

La coletividad como fator de desarrollo del niño deficiente. Obras escogidas .Fundamentos de Defectologia. Madrid: Visor4,1997c.

\section{Correpondência}

Roseli Albino dos Santos - Univerisdade de Taubaté, Departamento de Pedagogia. Rua Conselheiro Moreira de Barros, 203, Centro, CEP: 12010-080, Taubaté, São Paulo.

E-mail: roselialbino@uol.com.br - profa.suelene@gmail.com - merciaapoliveira@hotmail.com

Recebido em 23 de abril de 2013

Aprovado em 01 de outubro de 2013

Revista Educação Especial| v. $27 \mid$ n. 48 | p. 41-52 | jan./abr. 2014 